\title{
American ginseng suppresses Western diet- promoted tumorigenesis in model of inflammation-associated colon cancer: role of EGFR
}

\author{
Urszula Dougherty ${ }^{1}$, Reba Mustafi ${ }^{1}$, Yunwei Wang ${ }^{1}$, Mark W Musch' ${ }^{1}$, Chong-Zhi Wang ${ }^{2}$, Vani J Konda', \\ Anirudh Kulkarni', John Hart ${ }^{3}$, Glyn Dawson ${ }^{4}$, Karen E Kim¹, Chun-Su Yuan², Eugene B Chang ${ }^{1}$ and \\ Marc Bissonnette ${ }^{1 *}$
}

\begin{abstract}
Background: Western diets increase colon cancer risk. Epidemiological evidence and experimental studies suggest that ginseng can inhibit colon cancer development. In this study we asked if ginseng could inhibit Western diet ( $20 \%$ fat) promoted colonic tumorigenesis and if compound $\mathrm{K}$, a microbial metabolite of ginseng could suppress colon cancer xenograft growth.

Methods: Mice were initiated with azoxymethane (AOM) and, two weeks later fed a Western diet (WD, 20\% fat) alone, or WD supplemented with 250-ppm ginseng. After $1 \mathrm{wk}$, mice received 2.5\% dextran sulfate sodium (DSS) for 5 days and were sacrificed 12 wks after AOM. Tumors were harvested and cell proliferation measured by Ki67 staining and apoptosis by TUNEL assay. Levels of EGF-related signaling molecules and apoptosis regulators were determined by Western blotting. Anti-tumor effects of intraperitoneal compound $\mathrm{K}$ were examined using a tumor xenograft model and compound $\mathrm{K}$ absorption measured following oral ginseng gavage by UPLC-mass spectrometry. Effects of dietary ginseng on microbial diversity were measured by analysis of bacterial 16S rRNA.

Results: Ginseng significantly inhibited colonic inflammation and tumorigenesis and concomitantly reduced proliferation and increased apoptosis. The EGFR cascade was up-regulated in colonic tumors and ginseng significantly reduced EGFR and ErbB2 activation and Cox-2 expression. Dietary ginseng altered colonic microbial diversity, and bacterial suppression with metronidazole reduced serum compound K following ginseng gavage. Furthermore, compound K significantly inhibited tumor xenograft growth.

Conclusions: Ginseng inhibited colonic inflammation and tumorigenesis promoted by Western diet. We speculate that the ginseng metabolite compound $\mathrm{K}$ contributes to the chemopreventive effects of this agent in colonic tumorigenesis.
\end{abstract}

\section{Background}

Colon cancer arises from activating mutations in oncogenes and inactivating mutations in tumor suppressor genes. While hereditary forms of this disease arise from germline mutations such as loss of function mutations in the adenomatous polyposis coli (apc) gene, most colon cancers are sporadic and involve somatic

\footnotetext{
* Correspondence: mbissonn@medicine.bsd.uchicago.edu

'Department of Medicine, University of Chicago, Chicago IL USA

Full list of author information is available at the end of the article
}

mutations in $a p c$ or other genes. Environmental especially dietary factors are believed to contribute substantially to the risk of colon cancer development $[1,2]$. In this regard Western diets that are rich in Western style fats have been shown to promote colon cancer in experimental models $[2,3]$. We recently showed that epidermal growth factor receptors (EGFR) were required for tumor promotion by Western diet $[4,5]$. In the presence of a Western diet, EGFR signals increased protooncogene MYC and pro-inflammatory cyclooxygenase-2

\section{Ciomed Central}


(Cox-2). Since therapies for advanced cancers have limited efficacy, increasing attention has focused on chemopreventive approaches. Efforts to inhibit up-regulated EGFR signals that occur with Western diets might provide such a strategy to prevent these cancers.

Complementary and alternative medicines are widely used for a variety of health purposes. Many of these agents are well tolerated and some have served as lead compounds for developing more effective anti-cancer agents. Several retrospective case-control studies in Korea have supported chemopreventive effects of ginseng that appears to exert a broad spectrum of antitumor activities in humans [6-9]. Ginseng is a deciduous perennial plant belonging to the Araliaceae Ivy family that has been used for centuries in China and Korea as an anti-inflammatory agent [10]. Ginseng extracts contain ginsenosides as the major biologically active constituents, which are glycosides with a dammarane skeleton [11]. Many in vitro studies have demonstrated antitumor effects of ginseng alone or in combination with anti-cancer agents [12-15]. Antioxidant, anti-proliferative and anti-inflammatory effects of ginseng have been identified that may mediate the anti-tumor effects of this herb $[16,17]$. In addition, ginseng metabolites have been shown to inhibit EGFR-induced epithelial cell growth [18]. Moreover, a recent study in a model of colitis-associated colon cancer showed that ginseng reduced levels of phospho-active EGFR and phosphoactive ErbB2 as well as ERK, a down stream effector of EGFR, indicating ginseng could suppress EGFR signals in colonic tumorigenesis [19]. Given the requirement for EGFR in tumor promotion by Western diet, in the current study we investigated the ability of ginseng extract to inhibit colonic tumorigenesis under conditions of Western dietary stress. Tumors were induced with azoxymethane (AOM) followed by dextran sulfate sodium (DSS). Azoxymethane is a pro-carcinogen that is metabolized in the liver and further metabolized in the colon to an active alkylating agent, presumably a methyl carbonium ion [20]. This methyl donor leads to guanine methylations and eventually G to A transitions [21]. Proto-oncogenes targeted by AOM include activating mutations in $\beta$-catenin and K-Ras [21]. DSS is a polysulfated polymer that arrests colonic crypt cell re-generation leading to acute mucosal ulceration and clinical colitis that enhances tumorigenesis [22].

A number of studies have identified several bacterial metabolites of ginseng with biological activities [23-26]. These include 20-O- $\beta$-(D-glucopyranosyl)-20(S)-protopanaxadiol or compound $K$ that induces apoptosis in colon cancer cells [27-29]. Since the microbiome is essential for compound $\mathrm{K}$ generation, we examined the effects of dietary ginseng on microbial diversity and effects of broad-spectrum antibiotics on compound $\mathrm{K}$ bioavailability. Several ginsenosides have been shown to inhibit cancer growth, including colon cancer cells in tumor xenograft models [15,30-34]. To directly test compound $\mathrm{K}$ anti-tumor activity in colon cancer, we also examined the effects of this microbial metabolite of ginseng on colon cancer cell growth in a tumor xenograft model.

Taken together, in this study we demonstrate for the first time that ginseng can inhibit inflammation-associated colonic tumorigenesis in mice fed a tumor-promoting Western diet. Furthermore, compound K, a bacterial metabolite of ginsenoside Rb1, directly inhibits colon cancer cell growth in vivo.

\section{Methods}

\section{Materials}

HCT116 cells were obtained from ATCC (Manassas, VA). Male $\mathrm{A} / \mathrm{J}$ and immuno-deficient $n u / n u$ mice were obtained from Jackson Laboratories (Bar Harbor, ME). Azoxymethane was obtained from Midwest Research (Kansas City, MO), the NCI Chemical Carcinogen Reference Standard Repository. The sodium salt of dextran sulfate (MW 36,000-50,000) was obtained from MP Biomedicals (Solon, $\mathrm{OH}$ ). Ginseng extract was obtained from Wisconsin Ginseng Board (Wausau, WI). Compound K (20-O- $\beta$-D-glucopyranosyl-20(S)-protopanaxadiol) was purchased from ChromaDex (Irvine, CA). The molecular weight of compound $\mathrm{K}$ is 6,222.87. Harlan Teklad (Madison, WI) prepared AIN-76A and Western (20\% fat) and control chow diets. Details of the diet were as described [35]. RC-DC protein assay was obtained from Bio Rad (Hercules, CA). Rabbit polyclonal anti-Cox-2 antibodies (\#160106) were purchased from Cayman Chemicals (Ann Arbor, MI). Polyclonal antibodies to pAKT (\#9271) were obtained from Cell Signaling (Danvers, MA). Antibodies to pEGFR (SC-16802), pErbB2 (SC-12352R), pERK (SC-7383), Bax (SC-493), Bcl2 (SC-7382), c-Jun (SC-1694) and cyclin D1 (SC-718) were obtained from Santa Cruz Biotechnology (Santa Cruz, CA). Antibodies to phosphoactive EGFR (SC-16802) recognize human EGFR phosphorylated tyrosine 1092 and antibodies to phospho-active ErbB2 (SC-12352-R) recognize human ErbB2 phosphorylated tyrosine 1248 . Monoclonal antibodies to $\beta$-actin were purchased from Sigma-Aldrich (St. Louis, MO). Antibodies to p27Kip1 and p21Waf1 were purchased from BD Transduction Laboratories (San Jose, CA). PCNA antibodies were obtained from Biomeda Corp. (Foster City, CA). TUNEL assay kit was purchased from Millipore (Billerica, MA).

\section{Methods}

\section{Ginseng extraction and chemical analysis}

American ginseng root powder was obtained from Wisconsin Ginseng Board (Wausau, Wisconsin). Five 
hundred grams of ginseng was extracted in 10 vol 70\% ethanol under reflux for $2 \mathrm{~h}$ in a water bath kept at 90 $95^{\circ} \mathrm{C}$. The filtrate was collected and the extraction procedure repeated on the residue. The residue was discarded after the second extraction. The filtrates were combined and passed through filter paper. Filtrate was evaporated under vacuum. The extract was dissolved in $500 \mathrm{ml}$ water and extracted 4 times $(125 \mathrm{ml} \times 4)$ in water-saturated n-butanol. The n-butanol phase was evaporated under vacuum, and lyophilized. All solvents used for extraction were US pharmacopoeia (USP) purity. The ratio of starting material (dried American ginseng) to final ginseng extract was approximately 10:1. The ginsenosides in the extract were characterized by UF-HPLC as described [14,36]. The ginsenoside concentrations (mg/gram extract) were Rg1, 14.0; Re, 197.9; Rb1, 341.8; Rc, 34.2; Rb2, 4.6; Rb3, 6.8; Rd, 65.0; Rg3, 0.6 as reported [37].

\section{Tumor Induction}

Use of animals for these studies was approved under the guidelines of the Institutional Animal Care and Use Committee (IACUC) at University of Chicago, which complies with the guidelines outlined by the National Institutes of Health. A/J male mice weighing 20-22 grams were acclimated for 2 wks on AIN-76A chow. We followed a modified protocol to induce colitis-associated colon cancer [22]. Mice received a single dose of azoxymethane (AOM) $10 \mathrm{mg} / \mathrm{kg}$ body weight or saline (AOM vehicle). Two wks later mice were randomized to receive a Western diet (20\% fat) or Western diet supplemented with 250-ppm ethanol/butanol extracted American ginseng. Western diet was $20 \%$ fat and included beef tallow $(35 \mathrm{gm} / \mathrm{kg})$, lard $(30 \mathrm{gm} / \mathrm{kg})$ and corn oil $(80$ $\mathrm{gm} / \mathrm{kg}$ ). Detailed composition of WD was reported [35]. We calculated that the ginseng dose was approximately $0.875 \mathrm{mg}$ ginseng extract/mouse/day. One wk after starting Western diet, mice received 2.5\% DSS in the drinking water $\times 5$ days. DSS-induced clinical colitis was assessed as described [38]. It should be noted that there were no endoscopically visible tumors for several weeks after DSS. Mice were sacrificed 12 wks after AOM treatment and tumors and colonic mucosa harvested. The protocol is summarized in Figure 1A. A/J mice are very sensitive to AOM [39], and thus only one dose of AOM followed by one cycle of DSS was sufficient to induce tumors in these mice. Fifteen min prior to sacrifice mice were treated with peroxovanadate as described to lock in phospho-EGFR signals $[40,41]$. Tumors were divided and one aliquot was fixed in 10\% buffered formalin for histology. Colonic mucosa and another aliquot of tumor were flash frozen for Western blotting.

\section{Tumor histology}

Tumor histological features were assessed by a GI pathologist $(\mathrm{JH})$. Adenomas were defined as neoplastic lesions characterized by abnormal glandular architecture with branching or elongated crypts. Cytologically, these lesions exhibited hyperchromatic, elongated and pseudostratified nuclei with mildly increased nuclear to cytoplasmic ratios. Adenomas with carcinoma in situ exhibited marked glandular complexity, including areas with a cribriform configuration and marked cytological atypia, characterized by large irregular nuclei and loss of nuclear polarity.

\section{Mouse colonoscopy}

Colonoscopy was performed using Karl Storz-Endoskope to monitor colitis and tumor development as described [42]. The colonoscope was advanced $4 \mathrm{~cm}$ proximal to the anus. If needed, water was used to irrigate the colon. In some cases, the colonoscope was advanced to the cecum if there was no resistance. Careful visual inspection with white light was performed upon withdrawal. During endoscope withdrawal, lesions were described and endoscopic pictures captured. External 5 $\mathrm{mm}$ marking on the colonoscope were used to estimate lesion location within the colon.

\section{Western Blotting}

Proteins were extracted in SDS-containing Laemmli buffer, quantified by RC-DC protein assay and subjected to Western blotting as described (4). Briefly, proteins were separated by SDS-PAGE on 4-20\% resolving polyacrylamide gradient gel and electroblotted to PVDF membrane. Prestained molecular markers were included in each gel. Blots were incubated overnight at $4^{\circ} \mathrm{C}$ with specific primary antibodies followed by $1 \mathrm{hr}$ incubation with appropriate peroxidase-coupled secondary antibodies that were detected by enhanced chemiluminescence using X OMAT film. Xerograms were digitized using an Epson scanner (San Jose, CA) and band intensity quantified using UN-SCAN-IT gel software (V 5.3, Silk Scientific, Orem UT). Protein levels in tumors were normalized to $\beta$-actin levels and expressed as fold of control colonic mucosa (means $\pm \mathrm{SD}$ ). Protein lysates from tumors and control colonic mucosa with equal protein abundance as assessed by RC-DC assays showed comparable $\beta$-actin levels by Western blotting. Tumors of comparable stage (adenomas) were used for Western blotting comparisons.

\section{Immunostaining}

Five-micron sections were mounted on Vectabondcoated Superfrost Plus slides. Sections were heated to $60^{\circ} \mathrm{C}$ for $1 \mathrm{hr}$, deparaffinized by 3 washes $\times 5$ min in xylene, hydrated in a graded series of ethanol washes and rinsed in distilled water. Epitope retrieval for Ki67 was achieved by pressure cooker for $15 \mathrm{~min}$ in Tris-EDTA buffer, $\mathrm{pH} 9$ followed by 3 washes $\times 2 \mathrm{~min}$ in Tris-buffered saline with $0.1 \%$ Tween-20 (TBST). Endogenous peroxidase activity was quenched with methanol/H2O2 solution (0.5\%). Sections were washed 


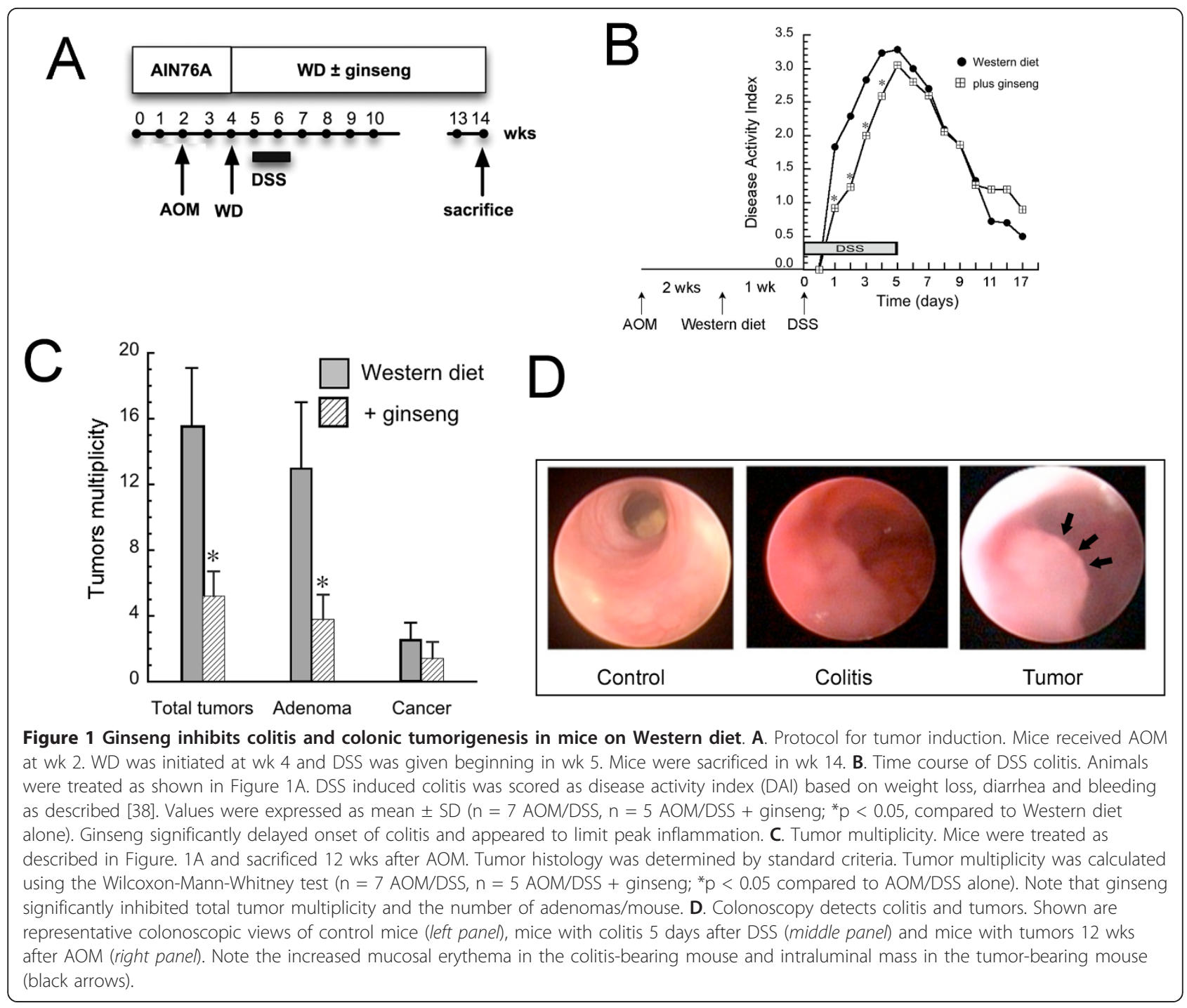

3 times in TBST $\times 2$ min and blocked in Protein Block for $20 \mathrm{~min}$. Sections were incubated with 1:300 dilution of anti-Ki67 antibodies for $1 \mathrm{hr}$ at room temperature. After 3 TBST washes, slides were incubated at room temperature with 1:200 dilution of biotinylated secondary antibodies for $30 \mathrm{~min}$. Antigen-antibody complexes were detected using an HRP labeled DAKO EnVision ${ }^{\mathrm{TM}}+$ System and 3,3'-diaminobenzidine as substrate. For negative controls, sections were incubated with isotype matched non-immune antibodies. After washing in distilled water, slides were stained with Gill's III hematoxylin, rinsed with water, dehydrated in ethanol and cleared with xylene. For TUNEL assay, epitopes were retrieved by treatment with protease 1 digestion for $10 \mathrm{~min}$ at room temperature. After blocking endogenous peroxidases with hydrogen peroxide, tissues were incubated in equilibration buffer and treated with terminal deoxynucleotidyl transferase (TdT) enzyme to detect TUNEL-positive nuclei as suggested by the manufacturer (Roche Scientific, Indianapolis IN). Tissues were then incubated with peroxidase-conjugated anti-digoxigenin antibodies and color developed with diaminobenzidine (DAB). After counterstaining with methyl green, sections were protected with cover slip secured with mounting medium. Tumors of comparable histology (adenomas) were used for all immunostaining comparisons.

\section{Immunostaining Quantitation}

Ki67 nuclear staining and TUNEL positive cells were quantified by the automated Aperio Scanning imaging system (Vista CA). Proliferation was expressed as \% nuclei positive for Ki67. Color-specific thresholds were used to determine brown (Ki67 positive) and blue (Ki67 negative) nuclei within the outlined regions of interest to calculate the fraction of positively stained nuclei. Cell death was scored as $\%$ nuclei positive for TUNEL. At 
least 5 fields per tumor and 3 tumors per group ( 50,000 cells/condition) were scanned for quantitation.

\section{Tumor Xenografts}

For tumor xenograft studies, HCT116 cells obtained from ATCC were cultured as described previously [5]. Cells $\left(5 \times 10^{\wedge} 6\right)$ were implanted subcutaneously into the flanks of athymic immunodeficient nude mice $(\mathrm{nu} / \mathrm{nu}$ mice). Tumors were allowed to grow for one week prior to treatment with compound K or vehicle (DMSO). Mice were treated daily with compound $\mathrm{K}(30 \mathrm{mg} / \mathrm{kg}$ body wt) or DMSO. Tumor dimensions were measured serially with a vernier calipers and tumor volume calculated as (width) ${ }^{2} \times$ length $/ 2$. Tumor size was estimated from volumes assuming a density of $1 \mathrm{gram} / \mathrm{ml}$. Mice were sacrificed and tumors harvested 4 wks after implantation.

\section{Analysis of microbial 16S rRNA}

Mice were randomized to receive Western diet or Western diet supplemented with 250 ppm ginseng. Two weeks after starting on the diet, fresh stool was collected and bacterial DNA extracted. Clone library preparation and sequencing analyses of bacterial genes encoding $16 \mathrm{~S}$ rRNA were performed as described [43]. 16S rRNA gene sequences were amplified from DNA samples using primers $8 \mathrm{~F}$ (5'-AGAGTTTGATCCTGGCT-CAG3') and 1492R (5'-GGTTACCTTGTTACGACTT-3') for the conserved domain of bacterial 16S rRNA. PCR reactions were performed for 30 cycles using Takara highfidelity Ex Taq (Takara Mirus Bio, Madison, WI, USA) with an annealing temperature of $58^{\circ} \mathrm{C}$. PCR products were purified by QIAquick gel extraction kit (Qiagen, Valencia, CA) and cloned into pCR-2.1-TOPO ${ }^{\circledR}$ vectors (Invitrogen, Carlsbad, CA) using the TOPO-TA Cloning Kit according to the manufacturer's instructions. From each library, 100 colonies were picked randomly and processed for DNA sequencing using $8 \mathrm{~F}$ as the sequencing primer.

\section{Sequence alignment and phylogenetic analysis}

The 16S rRNA gene sequences were analyzed as described previously [43]. Briefly, raw sequence data were processed by base-calling, quality-trimming and alignment, using the RDP pipeline server at the Ribosomal Database Project II (RDP-II) website http://rdp. cme.msu.edu/pipeline. Potential chimeric sequences were checked and excluded as appropriate using the SimRank 2.7 package available through the RDP. The RDP-II classifier analysis tool and NCBI BLAST tool were used to assign 16S rRNA sequences to the taxonomical hierarchy at phylum level. For principal coordinate analysis (PCA), all 16S rRNA gene sequences were imported using the ARB software package and aligned into a phylogenetic tree, which was used to perform clustering analysis without abundance weighting using online UniFrac. All sequences will be deposited in the GenBank nucleotide sequence databases post-publication.

\section{Measurements of $R b 1$ and compound $K$ in mouse sera}

Mice were given unsupplemented drinking water or drinking water supplemented with metronidazole $(600$ $\mu \mathrm{g} / \mathrm{ml}$ ) for 5 days. Mice were then gavaged with 500 $\mathrm{mg} / \mathrm{kg}$ ginseng extract. At indicated times mice were sacrificed and blood obtained for plasma measurements of ginsenoside Rb1 and compound $\mathrm{K}$ by UPLC/MSTOF analysis. Mouse plasma was mixed with $20 \mu \mathrm{L}$ of internal standard (digoxin, $10 \mu \mathrm{g} / \mathrm{ml}$ ). The plasma sample was diluted with $1 \mathrm{ml}$ of saline and purified by solid-phase extraction (SPE) with a Sep-Pak C8 Vac 3cc $500 \mathrm{mg}$ cartridge (Waters, Milford, MA). The purified eluate, containing ginsenosides and metabolites, was evaporated to dryness at $40^{\circ} \mathrm{C}$ under nitrogen and dissolved in $200 \mu \mathrm{L}$ methanol. Chromatographic separation was performed on an Agilent 1200 series (Agilent, Germany) liquid chromatographic system at $25^{\circ} \mathrm{C}$ using an Agilent ZorBax Extend-C18 UPLC column $(50 \times 2.1$ $\mathrm{mm}, 1.8 \mu \mathrm{m})$. The mobile phase consisted of $0.1 \%$ formic acid in water (A) and acetonitrile (B). Gradient elution started with $82 \%$ solvent $\mathrm{A}$ and $18 \%$ solvent $\mathrm{B}$, changed to $21 \% \mathrm{~B}$ for $6 \mathrm{~min}$, then changed to $26 \% \mathrm{~B}$ for $1 \mathrm{~min}$ and held for $2 \mathrm{~min}$; changed to $27 \% \mathrm{~B}$ for 4 min and held for $1 \mathrm{~min}$; changed to $30 \% \mathrm{~B}$ for $3 \mathrm{~min}$; changed to $36 \%$ B for $5 \mathrm{~min}$; changed to $50 \%$ B for 3 min and held for $2 \mathrm{~min}$; changed to $33 \% \mathrm{~B}$ for $5 \mathrm{~min}$. The flow rate was kept at $0.4 \mathrm{ml} / \mathrm{min}$, and the sample volume injected was set at $2 \mu \mathrm{L}$. The TOF/MS analysis was performed in full-scan mode with an electrospray ionization (ESI) source and the mass range was set at mass to charge ratio $(\mathrm{m} / \mathrm{z}) 100-1500$ in negative mode. The acquisition and analysis of data were controlled by Agilent LC-MS TOF software, version A.01.00 and Applied Biosystems/MDS-SCIEX Analyst QS software, respectively. A calibration curve was used to calculate the compound concentration in samples. The curve plots the concentration of the standard ( $x$-axis) against the area ratio of $\mathrm{Rb} 1$ or compound $\mathrm{K} /$ internal standard (y-axis). The measured sample area ratio then allows estimation of sample concentration from the calibration curve.

\section{Statistical Methods}

Continuous data were expressed as means $\pm \mathrm{SD}$, and compared using Student's t-test. Tumor multiplicity was defined as the average number of tumors in a given group. Tumor multiplicity was compared using negative binomial regression and significance calculated using the Wilcoxon-Mann-Whitney test [44]. All statistical analyses were performed using Stata v. 10, and p-values < 0.05 were considered statistically significant. 


\section{Results}

\section{Ginseng inhibits AOM/DSS-induced colitis and} tumorigenesis under Western diet

The study protocol is summarized in Figure 1A. As expected DSS induced clinical colitis as assessed by disease activity index that was scored as described [38]. As shown in Figure 1B, ginseng significantly delayed the onset of DSS-induced clinical colitis and appeared to reduce maximal inflammation. At the time of sacrifice there was minimal histological inflammation present. Ginseng significantly reduced tumor multiplicity from $15.6 \pm 3.1$ in the Western diet group to $5.1 \pm 2.3(\mathrm{p}<$ $0.05)$ in the group receiving Western diet and ginseng (Figure 1C). There were also significantly fewer adenomas in the ginseng group $(p<0.05)$, and a trend towards fewer cancers $(\mathrm{p}=0.08)$ as shown in Figure $1 \mathrm{C}$. During the study we examined mice by colonoscopy to monitor inflammation and tumor development. Representative colonoscopic views of control mice, mice with colitis and mice with colonic tumors are shown in Figure 1D.

\section{Ginseng inhibits proliferation and increases apoptosis in AOM/DSS tumors}

To elucidate the effects of ginseng on proliferation and apoptotic cell death we examined tumors for Ki67 and
Table 1 Ginseng inhibits proliferation and increases cell death in colonic tumors

\begin{tabular}{lll}
\hline Group & $\begin{array}{l}\text { Ki67 staining } \\
\text { (\% positive nuclei) }\end{array}$ & $\begin{array}{l}\text { Apoptosis } \\
\text { (\% TUNEL positive cells) }\end{array}$ \\
\hline Western diet (WD) & $29.2 \pm 7.3 \%$ & $8.0 \pm 2.7$ \\
WD + ginseng & $15.3 \pm 4.6 \% *$ & $11.9 \pm 4.0+$ \\
\hline
\end{tabular}

${ }^{*} \mathrm{p}<0.001$, compared to Western diet alone; $\mathrm{tp}<0.05$, compared to WD alone.

TUNEL staining. As shown in Figure 2, ginseng reduced proliferation and increased apoptotic cell death. Quantitation of proliferation and cell death in colonic tumors are summarized in Table 1 . Ginseng caused nearly a $50 \%$ reduction in proliferation and nearly a $50 \%$ increase in apoptosis.

\section{Effects of ginseng on EGFR signals and regulators of apoptosis}

To begin to dissect molecular signals potentially contributing to ginseng-induced changes in proliferation and cell death, we examined EGFR signals and apoptosis regulators. As shown in Figure 3, colonic tumors induced by AOM/DSS in mice on Western diet showed up-regulations of phospho-active-EGFR (pEGFR), pErbB2, pERK, and pAKT (Figure 3). Dietary ginseng significantly reduced these activations in tumors.

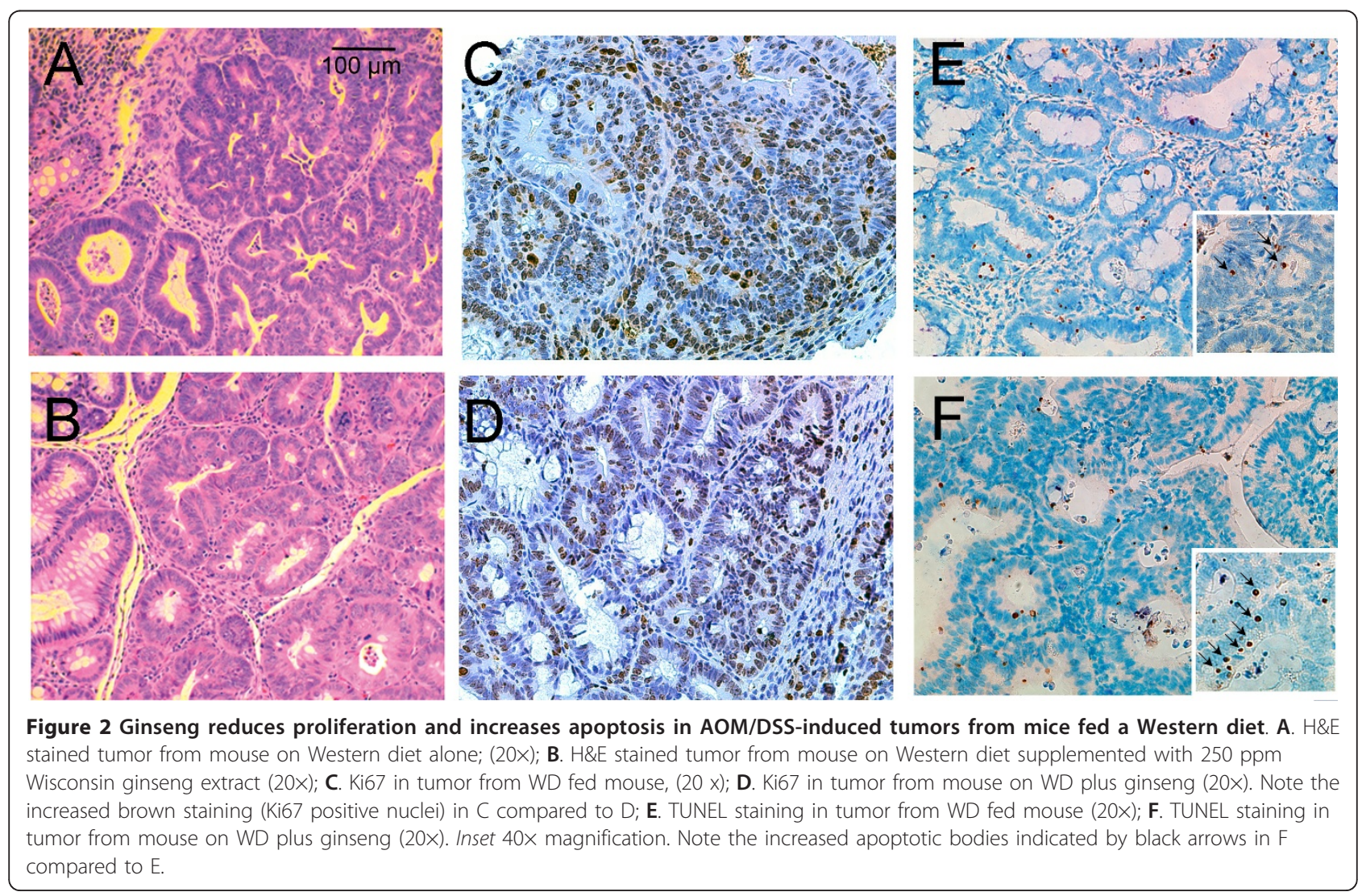




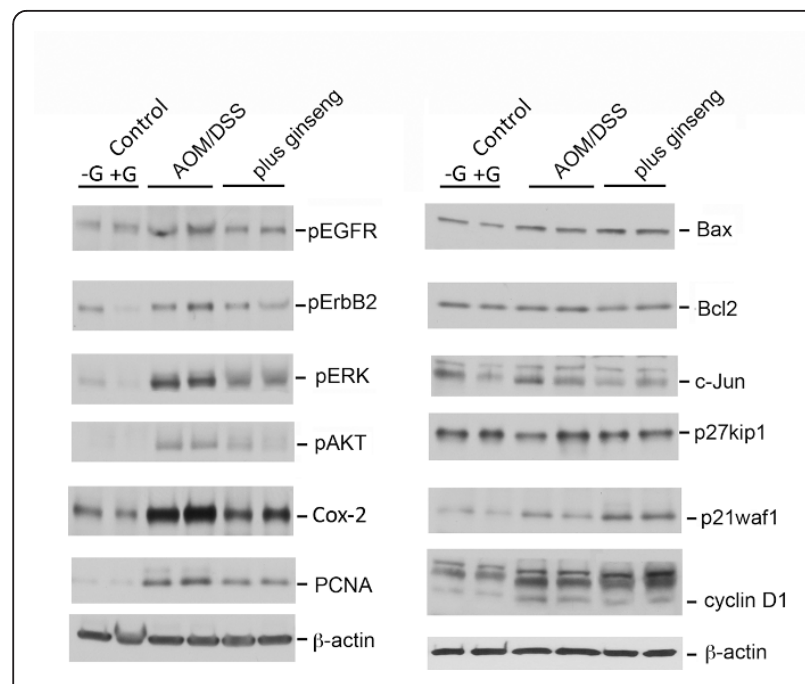

Figure 3 Ginseng inhibits EGFR signals and Cox-2 upregulation and increases pro-apoptotic Bax in AOM/DSS tumors. Control mucosa $(-G$, Western diet alone, $+G$, Western diet + ginseng) and colonic tumors were homogenized in Laemmli buffer and indicated proteins detected by Western blotting. Shown are representative control samples and tumors from each group. Quantitative densitometry is provided in Table 2.

Ginseng also increased cell cycle and apoptosis regulating $\mathrm{p} 21 \mathrm{Waf1}$ in tumors that is predicted to inhibit proliferation and increase apoptosis $[45,46]$. With respect to other apoptotic regulators, ginseng decreased anti-apoptotic Cox-2 and increased pro-apoptotic Bax, consistent with ginseng-induced increased apoptosis. Quantitative densitometry values are summarized in Table 2 .

\section{Absorption and biological effects of ginseng metabolite compound $\mathrm{K}$}

Several metabolites of ginseng require colonic microbiota for biosynthesis [47]. In recent preliminary studies we found that whereas the ginsenoside Rb1 had limited

Table 2 EGFR signals and apoptosis mediators

\begin{tabular}{lll}
\hline Protein & AOM/DSS & +ginseng \\
\hline pEGFR & $2.2 \pm 0.3^{*}$ & $1.1 \pm 0.2 \dagger$ \\
pErbB2 & $2.8 \pm 0.4^{*}$ & $1.6 \pm 0.1 \dagger$ \\
pERK & $8.3 \pm 0.1^{*}$ & $5.8 \pm 0.3^{*}, \dagger$ \\
pAKT & $7.2 \pm 0.3^{*}$ & $4.4 \pm 0.8^{*}, \dagger$ \\
Cox-2 & $3.1 \pm 0.3^{*}$ & $1.9 \pm 0.2^{*}, \dagger$ \\
PCNA & $10.7 \pm 1.2^{*}$ & $6.3 \pm 0.1^{*}, \dagger$ \\
Bax & $1.6 \pm 0.3$ & $2.0 \pm 0.1^{*}, \dagger$ \\
BCl2 & $1.1 \pm 0.1$ & $1.1 \pm 0.2^{+}$ \\
c-Jun & $1.2 \pm 0.2$ & $0.6 \pm 0.2^{\dagger}$ \\
p27Kip1 & $1.0 \pm 0.5$ & $0.9 \pm 0.1$ \\
p21Waf1 & $1.8 \pm 0.2$ & $3.8 \pm 0.1^{*}, \dagger$ \\
CCND1 & $2.9 \pm 0.6^{*}$ & $2.7 \pm 0.4^{*}$ \\
\hline
\end{tabular}

${ }^{*} p<0.05$, compared to vehicle treated on WD; $+p<0.05$ compared to AOM/ DSS on WD; $n=4$ tumors in each group. anti-proliferative and pro-apoptotic activity, 20-O- $\beta$-(Dglucopyranosyl)-20(S)-protopanaxadiol or compound K, a microbial metabolite of $\mathrm{Rb} 1$ potently suppressed colon cancer cell proliferation in vitro (C. Wang et al., manuscript submitted). To directly assess the anti-tumor effects of compound $\mathrm{K}$ we examined the ability of this bacterial metabolite of ginseng to inhibit tumor xenograft growth. The structure of compound $\mathrm{K}$ is shown in Additional File 1. As shown in Figure 4A, compound $\mathrm{K}$ potently suppressed growth of HCT116 cells in immunodeficient nude $(n u / n u)$ mice when administered by intraperitoneal route.

To address a colonic bacterial requirement for compound $\mathrm{K}$ synthesis we pretreated mice with metronidazole a broad-spectrum antibiotic or vehicle (control). Following 5 days treatment we measured ginsenoside $\mathrm{Rb} 1$ and compound $\mathrm{K}$ in the sera by mass spectrometry. As shown in Figure 4B, Rb1 absorption was not influenced by antibiotic treatment. In contrast, compound $\mathrm{K}$ was undetectable in antibiotic-treated mice, but readily detected in mouse sera from vehicle-treated mice (Figure $4 \mathrm{C}$ ). These results are consistent with a requirement for metronidazole-sensitive colonic bacteria for compound $\mathrm{K}$ synthesis.

\section{Ginseng alters colonic microbiome diversity}

While bacteria are required for metabolism of some ginsenosides, it is also possible that ginseng might alter the microbial flora since it is a substrate for some bacteria. To assess the effects that ginseng might have on the microflora, we compared colonic bacterial populations in mice on 2 wks of Western diet alone vs. those on Western diet plus $250 \mathrm{ppm}$ ginseng extract. As shown in Figure 4D, ginseng reduced the number of Tenericutes, while increasing the Bacteroidetes population. Principal coordinate analysis suggested that the microbial populations in mice receiving ginseng were markedly distinct from those on Western diet alone (Figure $4 \mathrm{E})$. These changes support our hypothesis that ginseng consumption might alter the colonic microbiome. Whether these changes influence microbial metabolic activity towards ginseng, including compound $\mathrm{K}$ biosynthesis, will require further study.

\section{Discussion}

We have shown for the first time that an extract of ginseng can inhibit colonic tumor development under conditions of a Western diet in a model of inflammationassociated colon cancer. These studies extend recent findings that ginseng can inhibit colonic tumorigenesis under standard dietary fat conditions [19]. We also observed that ginseng delayed the onset and appeared to lessen the severity of inflammation in this model in agreement with a prior study [48]. Since inflammation 


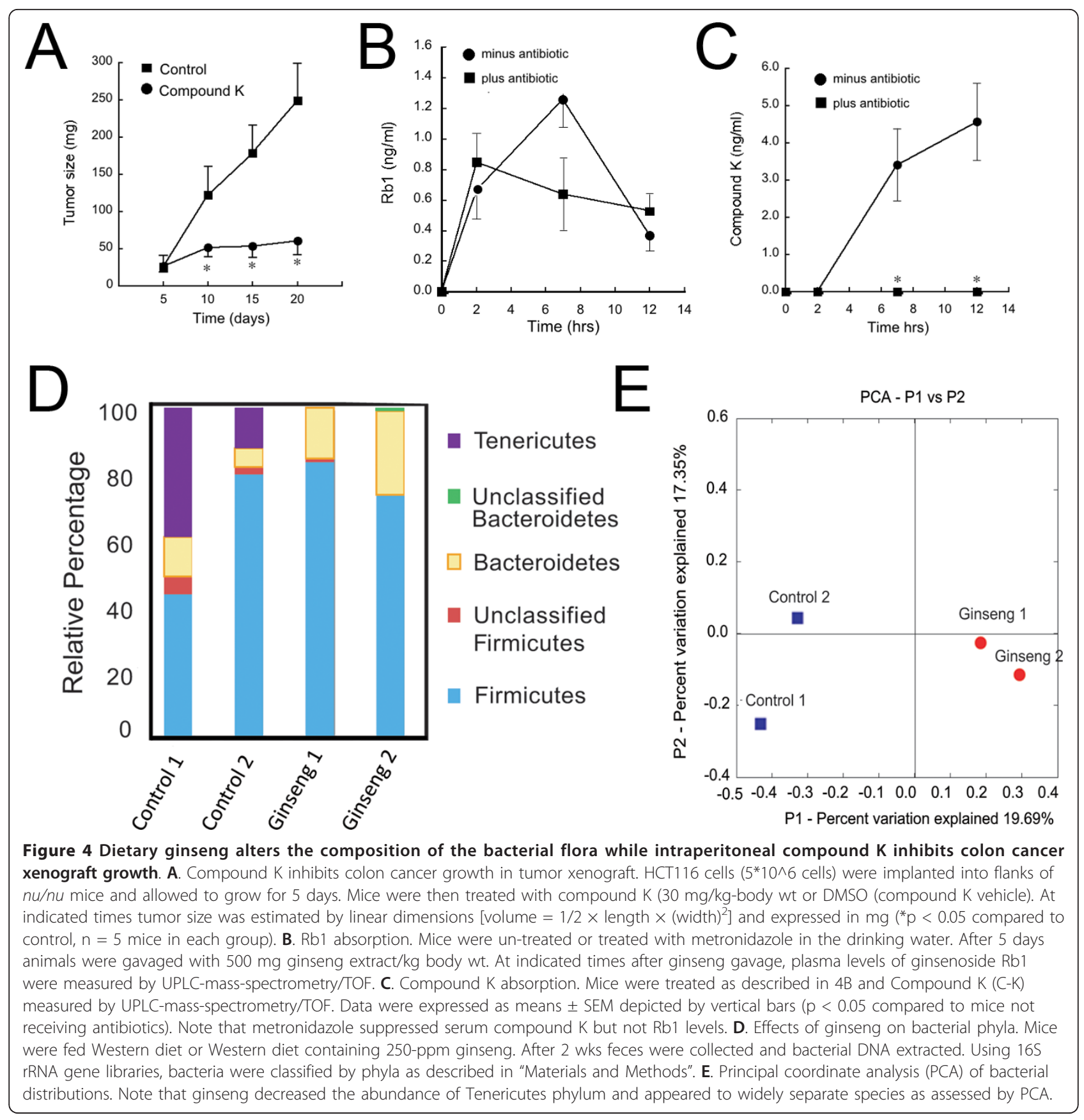

plays a key role in this model, the anti-cancer effects of ginseng likely derive in part from its ability to suppress inflammation, as also suggested by ginseng suppression of Cox-2 a molecular marker of inflammation [49]. Cox2 inhibition has been shown to directly suppress tumorigenesis in this model [50]. Ginseng appeared to inhibit tumor initiation, as tumor multiplicity and the number of adenomas were significantly reduced in the ginseng treated group. There was also a trend towards fewer cancers in the ginseng group, suggesting that this agent might inhibit tumor progression, but this did not reach statistical significance. In a study under standard dietary fat conditions ginseng inhibited tumor progression [19].

Ginseng supplementation reduced proliferation and increased apoptosis in tumors. Compared to tumors from the unsupplemented group, decreased PCNA expression in the ginseng group was consistent with reduced proliferation. Prior studies by our group and others have shown that ginseng or its metabolites induce anti-proliferative and pro-apoptotic effects in 
human cancer cells $[12,15,31,51,52]$. More recently, we demonstrated that compound $\mathrm{K}$, a microbial metabolite of ginsenoside Rb1, induced G1 cell cycle slowing and accelerated apoptosis of colon cancer cells (C. Wang et al., manuscript submitted). Compound $\mathrm{K}$ has also been shown to inhibit growth and increase apoptosis in a model of liver cancer metastasis [27].

To begin to elucidate cellular signaling pathways that mediate these anti-proliferative and pro-apoptotic effects we examined expression levels of several proto-oncogenes and tumor suppressors. We found in tumors from the unsupplemented group that EGFR signals, including pEGFR, pErbB2, pERK and pAKT were significantly increased. Ginseng significantly reduced increases in EGF receptor activation and inhibited these downstream effectors that are known to drive mitogenic and pro-survival signals in colon cancer [53,54]. Ginseng also increased p21Waf1, a cyclin-cdk inhibitor predicted to retard G1 - > S cell cycle progression. While we did not measure changes in $\mathrm{p} 53$, a major regulator of p21Waf1, this cyclin-cdk-dependent inhibitor can also regulate p53-independent pathways [46].

Among the regulators of apoptosis, we demonstrated that ginseng significantly reduced Cox-2 and increased pro-apoptotic Bax in tumors. Cox-2 is an EGFR effector in this model that suppresses apoptosis in colon cancer cells $[4,55]$. This pro-inflammatory molecule plays a critical role in both sporadic and inflammation-associated colonic tumorigenesis [56,57]. With respect to Bax, down-regulation of this protein has been suggested to predict colon cancer prognosis in early stage disease [58]. Changes in these regulators were consistent with increased apoptosis in tumors from ginseng-supplemented mice. Since we showed that EGFR signals were required for Western diet to promote colonic tumorigenesis $[4,5]$, we speculate that inhibition of this cascade plays a critical role in the chemopreventive effects of ginseng by limiting proliferation and increasing apoptosis in this model. As this commonly used and safe natural herb appears to inhibit diet-promoted colon cancer, ginseng might offer a novel chemopreventive strategy for colon cancer, particularly in Asia where there is widespread use of ginseng and increasing adoption of Westernized diets.

In recent preliminary in vitro studies we showed that the anti-proliferative and pro-apoptotic effects of the ginsenoside $\mathrm{Rb} 1$ were likely mediated by compound $\mathrm{K}$, a major microbial metabolite of Rb1. In agreement with these findings, others have shown that compound $\mathrm{K}$ induced apoptosis in colon cancer cells in vitro and inhibited hepatocellular tumor xenograft growth in vivo $[27,28]$. Compound $\mathrm{K}$ is derived from Panax ginsenoside $\mathrm{Rb} 1$ by the microbial enzyme geniposide-hydrolysing beta-D-glucosidase [47]. Antibiotic treatment suppressed the appearance of compound $\mathrm{K}$ in the serum. $\mathrm{Rb} 1$ and compound $\mathrm{K}$ appear to block IRAK- 1 and $\mathrm{NF} \kappa \mathrm{B}$ activation and thereby reduce pro-inflammatory cytokines, IL$1 \beta$, TNF- $\alpha$ and IL- 6 and cytokine effectors iNOS and Cox-2 in 2,4,6-trinitrobenzene sulfonic acid (TNBS)treated mice, another model of colitis [59]. To directly assess the anti-tumor effects of compound $\mathrm{K}$ in a colon cancer model we examined the effect of this compound on HCT116 tumor xenograft growth. Compound K significantly inhibited colon cancer growth. We speculate, therefore, that this microbial metabolite contributes to the chemopreventive efficacy of ginseng in the AOM/ DSS model. We plan to directly test this assertion in future studies using germ-free animals.

It will also be of interest to determine how hostgenetic and environmental factors interact with the colonic microbiome. In contrast to a bacterial requirement for compound $\mathrm{K}$ generation, bacteria do not appear to be necessary to activate AOM as colonocytes from germ free rats generated $\mathrm{AOM}$ from precursor $\mathrm{DMH}$ at least as fast as colonocytes from conventionally colonized rats [60]. Furthermore, AOM can induce tumors in germ free rodents [61]. In addition to an effect of the microbes on ginseng metabolism, ginseng in the diet might reshape the microbiome by serving as a metabolic substrate or an environmental modifier to enrich microbial species capable of using or responding to this agent. This could lead to increases in the capacity to metabolize ginseng to bioactive molecules such as compound $\mathrm{K}$. Thus, sustained use of ginseng by individuals might promote clinical efficacy by increasing metabolic conversion of relatively inert ginseng to bioactive components. Such investigations might suggest more effective dietary and probiotic approaches to enhance ginseng-based colon cancer chemoprevention.

\section{Conclusions}

Ginseng inhibits AOM/DSS induced colonic tumorigenesis promoted by a Western diet. Inhibition of EGFR signals and alterations in G1 cell cycle and apoptosis regulators appear to contribute to these chemopreventive effects. Studies in tumor xenografts suggest that compound $\mathrm{K}$, a microbial metabolite of ginseng, may mediate some of these effects of ginseng. Further study of this promising natural agent for chemoprevention of colon cancer is warranted.

The abbreviations used are: AOM, azoxymethane; compound K, 20-O- $\beta$-(D-glucopyranosyl)-20(S)-protopanaxadiol; Cox-2, cyclooxygenase-2; DAI, disease activity index; DSS, dextran sulfate sodium; EGFR, epidermal growth factor receptor; PCA, principal coordinate analysis; TUNEL, terminal transferase dUTP nick end labeling; UPLC-MS/TOF, ultra performance liquid 
chromatograph mass spectrometry/time of flight; WD, Western diet.

\section{Additional material}

Additional file 1: Compound K. A TIF image of the structure of compound $\mathrm{K}$.

\section{Acknowledgements}

These studies were funded in part by the following grants: P30DK42086 (E.C. B.) [Digestive Diseases Research Core Center], CA036745 (M.B.), NIH/NCCAM grants AT004418 and AT005362 (C-S.Y.), Samuel Freedman Research Laboratories for Gastrointestinal Cancer Research and the University of Chicago Comprehensive Cancer Center.

\section{Author details}

${ }^{1}$ Department of Medicine, University of Chicago, Chicago IL USA. ${ }^{2}$ Tang Center for Herbal Medicine Research, and Department of Anesthesia \& Critical Care, University of Chicago, Chicago IL USA. ${ }^{3}$ Department of Pathology, University of Chicago, Chicago IL USA. ${ }^{4}$ Department of Pediatrics, University of Chicago, Chicago, Illinois 60637, USA.

\section{Authors' contributions}

UD carried out the AOM/DSS experiments and tumor xenograft studies and tissue Western blotting and immunostaining and assisted with mouse colonoscopy. RM prepared HCT116 cells for tumor xenograft studies. YW extracted fecal microbial DNA, prepared clone libraries and sequenced $16 \mathrm{~S}$ rDNA. He also carried out sequence alignment and phylogenetic characterization using principal coordinate analysis. MWM helped conceive the study, and participated in its design and coordination and helped draft the manuscript. CSW extracted ginseng and analyzed dietary ginsenoside content and measured ginsenosides in blood. VJK carried out mouse colonoscopies and endoscopic assessment of inflammation and tumors. AK assisted VJK with colonoscopies and assisted UD with tissue sectioning and staining. JH provided all histological assessments of inflammation and neoplasia. GD assisted with ginseng extraction and purification and study design and interpretation. KEK helped conceive the study and helped draft the manuscript. CSY helped conceive the study, participated in its design and guided ginsenoside analyses and helped draft the manuscript. EBC helped conceive the study, participated in its design and coordination, guided analysis of the microbiome and helped draft the manuscript. MB helped conceive the study, participated in its design and coordination, guided the in vivo AOM/DSS and tumor xenograft studies and helped draft the manuscript. All authors read and approved the final manuscript.

\section{Competing interests}

The authors declare that they have no competing interests.

Received: 21 August 2011 Accepted: 9 November 2011 Published: 9 November 2011

\section{References}

1. Yang K, Kurihara N, Fan K, Newmark H, Rigas B, Bancroft L, Corner G, Livote $E$, Lesser $M$, Edelmann W, et al: Dietary induction of colonic tumors in a mouse model of sporadic colon cancer. Cancer Res 2008, 68:7803-7810

2. Newmark HL, Yang K, Kurihara N, Fan K, Augenlicht LH, Lipkin M: Westernstyle diet-induced colonic tumors and their modulation by calcium and vitamin D in C57BI/6 mice: a preclinical model for human sporadic colon cancer. Carcinogenesis 2009, 30:88-92.

3. Singh J, Hamid R, Reddy BS: Dietary fat and colon cancer: modulating effect of types and amount of dietary fat on ras-p21 function during promotion and progression stages of colon cancer. Cancer Res 1997, 57:253-258.

4. Dougherty U, Cerasi D, Taylor I, Kocherginsky M, Tekin U, Badal S, Aluri L, Sehdev A, Cerda S, Mustafi R, et al: Epidermal growth factor receptor is required for colonic tumor promotion by dietary fat in the azoxymethane/dextran sulfate sodium model: roles of transforming growth factor-alpha and PTGS2. Clin Cancer Res 2009, 15:6780-6789.

5. Zhu H, Dougherty U, Robinson V, Mustafi R, Pekow J, Kupfer S, Li YC, Hart J, Goss K, Fichera A, et al: EGFR signals downregulate tumor suppressors miR-143 and miR-145 in Western diet-promoted murine colon cancer: role of G1 regulators. Mol Cancer Res 2011, 9:960-975.

6. Yun TK, Choi SY: Preventive effect of ginseng intake against various human cancers: a case-control study on 1987 pairs. Cancer Epidemiol Biomarkers Prev 1995, 4:401-408.

7. Yun TK, Zheng S, Choi SY, Cai SR, Lee YS, Liu XY, Cho K, Park KY: Nonorgan-specific preventive effect of long-term administration of Korean red ginseng extract on incidence of human cancers. J Med Food 2010, 13:489-494.

8. Yun TK, Choi SY: Non-organ specific cancer prevention of ginseng: a prospective study in Korea. Int J Epidemiol 1998, 27:359-364.

9. Yun TK: Experimental and epidemiological evidence on non-organ specific cancer preventive effect of Korean ginseng and identification of active compounds. Mutat Res 2003, 523-524:63-74.

10. Qi LW, Wang CZ, Yuan CS: American ginseng: potential structure-function relationship in cancer chemoprevention. Biochem Pharmacol 2010, 80:947-954.

11. Shibata S: Chemistry and cancer preventing activities of ginseng saponins and some related triterpenoid compounds. J Korean Med Sci 2001, 16(Suppl):S28-37.

12. Wang CZ, Li XL, Wang QF, Mehendale SR, Fishbein AB, Han AH, Sun S, Yuan CS: The mitochondrial pathway is involved in American ginsenginduced apoptosis of SW-480 colon cancer cells. Oncol Rep 2009, 21:577-584.

13. Luo X, Wang CZ, Chen J, Song WX, Luo J, Tang N, He BC, Kang Q, Wang Y, Du W, et al: Characterization of gene expression regulated by American ginseng and ginsenoside Rg3 in human colorectal cancer cells. Int J Oncol 2008, 32:975-983.

14. Wang CZ, Aung HH, Ni M, Wu JA, Tong R, Wicks S, He TC, Yuan CS: Red American ginseng: ginsenoside constituents and antiproliferative activities of heat-processed Panax quinquefolius roots. Planta Med 2007 73:669-674.

15. Xie JT, Wang CZ, Zhang B, Mehendale SR, Li XL, Sun S, Han AH, Du W, He TC, Yuan CS: In vitro and in vivo anticancer effects of American ginseng berry: exploring representative compounds. Biol Pharm Bull 2009, 32:1552-1558.

16. Keum YS, Park KK, Lee JM, Chun KS, Park JH, Lee SK, Kwon H, Surh YJ: Antioxidant and anti-tumor promoting activities of the methanol extract of heat-processed ginseng. Cancer Lett 2000, 150:41-48.

17. Surh YJ, Na HK, Lee JY, Keum YS: Molecular mechanisms underlying antitumor promoting activities of heat-processed Panax ginseng C.A. Meyer. J Korean Med Sci 2001, 16(Suppl):S38-41.

18. Han HJ, Yoon BC, Lee SH, Park SH, Park JY, Oh YJ, Lee YJ: Ginsenosides inhibit EGF-induced proliferation of renal proximal tubule cells via decrease of c-fos and c-jun gene expression in vitro. Planta Med 2002, 68:971-974.

19. Cui $X$, Jin $Y$, Poudyal D, Chumanevich AA, Davis T, Windust A, Hofseth A Wu W, Habiger J, Pena E, et al: Mechanistic insight into the ability of American ginseng to suppress colon cancer associated with colitis. Carcinogenesis 2010, 31:1734-1741.

20. Fiala ES: Investigations into the metabolism and mode of action of the colon carcinogens 1,2-dimethylhydrazine and azoxymethane. Cancer 1977, 40:2436-2445.

21. Takahashi M, Wakabayashi K: Gene mutations and altered gene expression in azoxymethane-induced colon carcinogenesis in rodents. Cancer Sci 2004, 95:475-480.

22. Tanaka T, Kohno H, Suzuki R, Yamada Y, Sugie S, Mori H: A novel inflammation-related mouse colon carcinogenesis model induced by azoxymethane and dextran sodium sulfate. Cancer Sci 2003, 94:965-973.

23. Hasegawa $H$, Sung $J H$, Matsumiya $S$, Uchiyama M: Main ginseng saponin metabolites formed by intestinal bacteria. Planta Med 1996, 62:453-457.

24. Lee BH, Lee SJ, Hur JH, Lee S, Sung JH, Huh JD, Moon CK: In vitro antigenotoxic activity of novel ginseng saponin metabolites formed by intestinal bacteria. Planta Med 1998, 64:500-503.

25. Bae EA, Han MJ, Kim EJ, Kim DH: Transformation of ginseng saponins to ginsenoside Rh2 by acids and human intestinal bacteria and biological activities of their transformants. Archives of pharmacal research 2004, 27:61-67. 
26. Hasegawa $\mathrm{H}$ : Proof of the mysterious efficacy of ginseng: basic and clinical trials: metabolic activation of ginsenoside: deglycosylation by intestinal bacteria and esterification with fatty acid. Journal of pharmacological sciences 2004, 95:153-157.

27. Song G, Guo S, Wang W, Hu C, Mao Y, Zhang B, Zhang H, Hu T: Intestinal metabolite compound $\mathrm{K}$ of ginseng saponin potently attenuates metastatic growth of hepatocellular carcinoma by augmenting apoptosis via a Bid-mediated mitochondrial pathway. J Agric Food Chem 2010, 58:12753-12760.

28. Lee IK, Kang KA, Lim CM, Kim KC, Kim HS, Kim DH, Kim BJ, Chang WY, Choi JH, Hyun JW: Compound K, a metabolite of ginseng saponin, induces mitochondria-dependent and caspase-dependent apoptosis via the generation of reactive oxygen species in human colon cancer cells. Int J Mol Sci 2010, 11:4916-4931.

29. Cho SH, Chung KS, Choi JH, Kim DH, Lee KT: Compound K, a metabolite of ginseng saponin, induces apoptosis via caspase-8-dependent pathway in HL-60 human leukemia cells. BMC Cancer 2009, 9:449.

30. Park D, Bae DK, Jeon JH, Lee J, Oh N, Yang G, Yang YH, Kim TK, Song J, Lee $\mathrm{SH}$, et al: Immunopotentiation and antitumor effects of a ginsenoside $\mathrm{Rg}$ (3)-fortified red ginseng preparation in mice bearing H460 lung cancer cells. Environ Toxicol Pharmacol 2011, 31:397-405.

31. He BC, Gao JL, Luo X, Luo J, Shen J, Wang L, Zhou Q, Wang YT, Luu HH, Haydon RC, et al: Ginsenoside Rg3 inhibits colorectal tumor growth through the down-regulation of Wnt/ss-catenin signaling. Int J Oncol 2011, 38:437-445.

32. Yoo JH, Kwon HC, Kim YJ, Park JH, Yang HO: KG-135, enriched with selected ginsenosides, inhibits the proliferation of human prostate cancer cells in culture and inhibits xenograft growth in athymic mice. Cancer Lett 2010, 289:99-110.

33. Wang W, Rayburn ER, Hao M, Zhao Y, Hill DL, Zhang R, Wang H: Experimental therapy of prostate cancer with novel natural product anti-cancer ginsenosides. Prostate 2008, 68:809-819.

34. Popov AM, Atopkina LN, Uvarova NI, Elyakov GB: The antimetastatic and immunomodulating activities of ginseng minor glycosides. Dokl Biochem Biophys 2001, 380:309-312.

35. Dougherty U, Cerasi D, Taylor I, Kocherginsky M, Tekin U, Badal S, Aluri L, Sehdev A, Cerda S, Mustafi R, et al: Epidermal growth factor receptor is required for colonic tumor promotion by dietary fat in the azoxymethane/dextran sulfate sodium model: roles of transforming growth factor-a and PTGS2. Clin Cancer Res 2009, 15:6780-6789.

36. Wang CZ, Wu JA, McEntee E, Yuan CS: Saponins composition in American ginseng leaf and berry assayed by high-performance liquid chromatography. J Agric Food Chem 2006, 54:2261-2266.

37. Wang CZ, Ni M, Sun S, Li XL, He H, Mehendale SR, Yuan CS: Detection of adulteration of notoginseng root extract with other panax species by quantitative HPLC coupled with PCA. J Agric Food Chem 2009, 57:2363-2367

38. Cooper HS, Murthy SN, Shah RS, Sedergran DJ: Clinicopathologic study of dextran sulfate sodium experimental murine colitis. Lab Invest 1993, 69:238-249.

39. Nambiar PR, Girnun G, Lillo NA, Guda K, Whiteley HE, Rosenberg DW: Preliminary analysis of azoxymethane induced colon tumors in inbred mice commonly used as transgenic/knockout progenitors. Int J Oncol 2003, 22:145-150.

40. Ruff SJ, Chen K, Cohen S: Peroxovanadate induces tyrosine phosphorylation of multiple signaling proteins in mouse liver and kidney. J Biol Chem 1997, 272:1263-1267.

41. Fitch KR, McGowan KA, van Raamsdonk CD, Fuchs $H$, Lee D, Puech A, Herault Y, Threadgill DW, Hrabe de Angelis M, Barsh GS: Genetics of dark skin in mice. Genes Dev 2003, 17:214-228.

42. Becker C, Fantini MC, Neurath MF: High resolution colonoscopy in live mice. Nat Protoc 2006, 1:2900-2904.

43. Wang Y, Devkota S, Musch MW, Jabri B, Nagler C, Antonopoulos DA, Chervonsky A, Chang EB: Regional mucosa-associated microbiota determine physiological expression of TLR2 and TLR4 in murine colon. PLoS One 2010, 5:e13607.

44. Drinkwater NR, Klotz JH: Statistical methods for the analysis of tumor multiplicity data. Cancer Res 1981, 41:113-119.

45. Gartel AL, Serfas MS, Tyner AL: p21-negative regulator of the cell cycle. Proc Soc Exp Biol Med 1996, 213:138-149.
46. Mahyar-Roemer M, Roemer K: p21 Waf1/Cip1 can protect human colon carcinoma cells against p53-dependent and p53-independent apoptosis induced by natural chemopreventive and therapeutic agents. Oncogene 2001, 20:3387-3398.

47. Akao T, Kida H, Kanaoka M, Hattori M, Kobashi K: Intestinal bacterial hydrolysis is required for the appearance of compound $\mathrm{K}$ in rat plasma after oral administration of ginsenoside $\mathrm{Rb} 1$ from Panax ginseng. $J$ Pharm Pharmacol 1998, 50:1155-1160.

48. Jin Y, Kotakadi VS, Ying L, Hofseth AB, Cui X, Wood PA, Windust A, Matesic LE, Pena EA, Chiuzan $C$, et al: American ginseng suppresses inflammation and DNA damage associated with mouse colitis. Carcinogenesis 2008, 29:2351-2359.

49. Hofseth $L$, Wargovich MJ: Inflammation, cancer, and targets of ginseng. J Nutr 2007, 137:183S-185S.

50. Kohno H, Suzuki R, Sugie S, Tanaka T: Suppression of colitis-related mouse colon carcinogenesis by a COX-2 inhibitor and PPAR ligands. BMC Cancer 2005, 5:46

51. King ML, Murphy LL: Role of cyclin inhibitor protein p21 in the inhibition of HCT116 human colon cancer cell proliferation by American ginseng (Panax quinquefolius) and its constituents. Phytomedicine 2010, 17:261-268.

52. Wakabayashi C, Murakami K, Hasegawa H, Murata J, Saiki I: An intestinal bacterial metabolite of ginseng protopanaxadiol saponins has the ability to induce apoptosis in tumor cells. Biochem Biophys Res Commun 1998, 246:725-730.

53. Sebolt-Leopold JS, Dudley DT, Herrera R, Van Becelaere K, Wiland A, Gowan RC, Tecle H, Barrett SD, Bridges A, Przybranowski S, et al: Blockade of the MAP kinase pathway suppresses growth of colon tumors in vivo. Nat Med 1999, 5:810-816.

54. Altomare DA, Testa JR: Perturbations of the AKT signaling pathway in human cancer. Oncogene 2005, 24:7455-7464.

55. DuBois RN, Shao J, Tsujii M, Sheng H, Beauchamp RD: G1 delay in cells overexpressing prostaglandin endoperoxide synthase-2. Cancer Res 1996, 56:733-737.

56. Fukata M, Chen A, Vamadevan AS, Cohen J, Breglio K, Krishnareddy S, Hsu D, Xu R, Harpaz N, Dannenberg AJ, et al: Toll-like receptor-4 promotes the development of colitis-associated colorectal tumors. Gastroenterology 2007, 133:1869-1881.

57. Williams CS, Tsujii M, Reese J, Dey SK, DuBois RN: Host cyclooxygenase-2 modulates carcinoma growth. J Clin Invest 2000, 105:1589-1594.

58. Nehls O, Hass HG, Okech T, Zenner S, Hsieh CJ, Sarbia M, Borchard F, Gruenagel HH, Gaco V, Porschen R, et al: Prognostic implications of BAX protein expression and microsatellite instability in all non-metastatic stages of primary colon cancer treated by surgery alone. Int I Colorectal Dis 2009, 24:655-663.

59. Joh EH, Lee IA, Jung IH, Kim DH: Ginsenoside Rb1 and its metabolite compound $\mathrm{K}$ inhibit IRAK-1 activation-the key step of inflammation. Biochem Pharmacol 2011, 82:278-286.

60. Glauert HP, Bennink MR: Metabolism of 1,2-dimethylhydrazine by cultured rat colon epithelial cells. Nutr Cancer 1983, 5:78-86.

61. Vannucci L, Stepankova R, Kozakova H, Fiserova A, Rossmann P, TlaskalovaHogenova $\mathrm{H}$ : Colorectal carcinogenesis in germ-free and conventionally reared rats: different intestinal environments affect the systemic immunity. Int J Oncol 2008, 32:609-617.

\section{Pre-publication history}

The pre-publication history for this paper can be accessed here: http://www.biomedcentral.com/1472-6882/11/111/prepub

doi:10.1186/1472-6882-11-111

Cite this article as: Dougherty et al:: American ginseng suppresses Western diet-promoted tumorigenesis in model of inflammationassociated colon cancer: role of EGFR. BMC Complementary and Alternative Medicine 2011 11:111. 